\title{
Deniz üstü Rüzgâr Enerji Santrallerinde Rüzgâr Türbini Çıkış Gücü Hesabında Temel İz Etkisinin Değerlendirilmesi için Bir Model
}

\author{
İbrahim ÇELİK ${ }^{1 *}$, Ceyhun YILDIZ1 ${ }^{\text {, Mustafa ŞEKKELİ }}{ }^{2}$ \\ ${ }^{1}$ Kahramanmaraş İstiklal Üniversitesi, Elbistan Meslek Yüksekokulu, Elektrik ve Enerji Bölümü, K. Maraş, Türkiye \\ ${ }^{2}$ Kahramanmaraş Sütçü İmam Üniversitesi, Mühendislik Mimarlık Fakültesi, Elektrik Elektronik Mühendisliği Bölümü, \\ K. Maraş, Türkiye
}

Geliş Tarihi: 23.02 .2019

"Sorumlu Yazar: icelik@ksu.edu.tr Kabul Tarihi: 09.04.2019

\section{$\ddot{\mathbf{O z}}$}

Deniz üstü Rüzgâr enerjisi santrali (RES) kurulumunda en önemli konulardan birisi de rüzgâr türbinlerinin iz etkisidir. $\mathrm{Bu}$ durum RES'in yıllık üretimini düşürmektedir. Bu nedenle RES kurulumunda iz etkisi sonucu meydana gelen üretim kaybı dikkate alınarak RES kurulumu gerçekleştirilmelidir. Günümüzde iz etkisi hesabında birçok yöntem kullanılmaktadır. Bu yöntemler arasında basit ve yüksek derecede doğruluğa sahip olan Jensen yöntemi daha çok tercih edilmektedir. Bu çalışmada, iki rüzgâr türbini arasındaki iz etkisi, bir bölgede aynı yükseklikteki değişken rüzgâr hızları ve frekansları için Jensen yöntemi kullanılarak modellenmiştir. Model, Matris Laboratuvarı (MATLAB) yazılım geliştirme ortamında oluşturulmuştur. Ayrıca oluşturulan modeli doğrulamak için Rüzgâr Atlası Analiz ve Uygulama Programı (WAsP) yazılımı kullanılmıştır. Bu yazılımda iki rüzgâr türbini deniz kıyısında uzakta bir bölgeye yerleştirilmiştir. Bu duruma ilişkin türbinlerin brüt üretim ve net üretim değerleri hesaplanmıştır. MATLAB modeli sonuçları ve ticari olarak kullanılan WAsP modeli sonuçları karşılaştırıldığında yaklaşık olarak aynı üretim değerleri elde edilmiştir. Bu sonuçlar geliştirilen modelin deniz üstü RES’lerde yapılacak hesaplamalarda kullanılabileceğini göstermektedir.

Anahtar Kelimeler: İz etkisi, Jensen modeli, Rüzgar Enerjisi Santrali.

\section{A Model for Evaluating the Basic Wake Effect in the Calculation of Wind Turbine Power Output on Offshore Wind Power Plant}

\begin{abstract}
One of the most important topics of offshore Wind Power Plant (WPP) installation is the wake effect of the wind turbines on each other. This situation reduces annual energy production of WPP. WPP installation should be performed by considering the loss of production due to the wake effect. Nowadays, many methods are used for calculation of wake effect. Among these methods, the Jensen method is mostly preferred due to the simple and high degree of accuracy. In this study, Wake effect between two wind turbines is modeled by using Jensen method for variable wind velocities and frequencies at the same elevation in a region. The model is formed in the Matrix Laboratory (MATLAB) software development environment. Also, Wind Atlas Analysis and Application Program (WAsP) software is used to verify the former model. In this software, two wind turbines are placed in offshore region. In this case, gross and net production values of turbines were calculated. When the results of MATLAB and commercially used WAsP model results were compared, the approximately same production values were obtained. These results show that the developed model can be used in calculations in offshore WPP.
\end{abstract}

Keywords: Wake effect, Jensen model, Wind Power Plant. 


\section{Giriş}

Dünyada, deniz üstü rüzgâr enerjisi santrali (RES) kullanımı her geçen gün artmaktadır. Avrupa'da 2018 yılı sonunda deniz üstü RES Kurulu gücü 16 GW'a ulaşmıştır. 2018'den 2027'ye kadar ise bölgede kurulu gücün 47 GW'a ulaşması beklenmektedir. Bu durum deniz üstü RES'lerin kurulumunu önemli bir konu haline getirmiştir (Foxwell, 2019).

Bir deniz üstü RES'in yıllık üretimini etkileyen en büyük etkenlerden birisi de iz etkisidir. Bir RES'teki her türbinin aşağıya doğru oluşan bir iz etkisi alanı bulunmaktadır. Bu etki RES'in yıllık üretiminin düşmesine sebep olmaktadır. Ayrıca iz etkisine daha fazla maruz kalan rüzgâr türbinlerde oluşan yüksek türbülans seviyesinden dolayı rüzgâr türbinlerinin kullanım ömrü azalmaktadır (Vermeer ve ark., 2003; Barthelmie ve ark., 2009; Porte-Agel ve ark., 2013).

Son yıllarda iz etkisini hesaplamak için sayısal ve deneysel olarak birçok yöntem geliştirilmiştir (Crespo ve ark., 1999; Marmidis ve ark., 2008; Emami ve ark., 2010; Asta ve ark., 2013; Turner ve ark., 2014;). Bu yöntemler doğru sonuçlar vermesine rağmen, basit analitik yöntemler, rüzgâr türbini iz etkisi hesabında ve iz etkisinin enerji üretimi üzerindeki etkilerini tahmin etmede daha yaygın olarak kullanılmaktadır (Katic ve ark., 1986; Fradsen, 1992; Kiranoudis ve Maroulis, 1997; Kusiak ve Song, 2010). Jensen modeli ise basit ve kullanımının kolay olmasından dolayı analitik hesaplama yöntemleri arasında ön plana çıkmaktadır ( Shakoora ve ark, 2016; Pena, 2016; Hao ve ark, 2016). Bu model ticari olarak kullanılan WAsP (Tian ve ark., 2014), WindPRO (Zhang, 2015), WindSim (Crastoa ve ark., 2012) gibi birçok yazılımda kullanılmaktadır.

Bu çalışmanın amacı deniz üstü RES’te iki rüzgâr türbini arasında iz etkisinden dolayı meydana gelebilecek üretim kaybını hesaplayabilmek için bir enerji üretim modeli oluşturmaktır. Bu modeli oluşturabilmek amacıyla Jensen modeli kullanılmıştır. Modeli oluşturulurken WAsP ortamından belirlenen bölgeye ait saha verileri ve türbine ait parametreler kullanılmıştır. Bu şekilde oluşturulan model ile WAsP sonuçları kıyaslanarak modelin etkinliği incelenmiştir.

Bu çalışma dört bölümden oluşmaktadır. İlk bölümde konu genel olarak anlatılmış, kısa bir literatür özeti ile beraber çalışmada kullanılan yöntemden bahsedilmiştir. İkinci bölümde ise iz etkisi anlatılarak Jensen iz etkisi modeli ile türbin yıllık enerji üretimi hesabı incelenmiştir. Ayrıca belirlenen bölgeye ait saha verileri ve türbine ait parametreler verilmiştir. Üçüncü bölümde iz etkisinin MATLAB modeli sonuçları ile ticari bir yazılım olan WAsP sonuçları kıyaslanmıştır. Son bölümde ise elde edilen sonuçlar değerlendirilmiştir. 


\section{Materyal ve Metot}

Deniz üstü RES'lerde rüzgâr türbinlerinin birbirlerine iz etkisi bulunmaktadır. Türbinlerde iz düşümü etkisi sebebiyle bir üretim kaybı meydana gelmektedir. Bu üretim kaybı, bir rüzgâr türbinin net enerji üretim hesabında önemli bir konudur. Bu çalışmada iz düşümü etkisinden dolayı türbin üretiminde meydana gelecek üretim kaybını hesaplayabilmek için bir enerji üretim modeli sunulmuştur. Bu model oluşturulurken Jensen iz etkisinden faydalanılmıştır. Modelde belirli bir bölge için saha verileri ve gerçek bir rüzgâr türbini parametreleri kullanılmıştır.

Bu bölümde, ilk olarak iz etkisi anlatılmış ve daha sonra rüzgâr türbini yıllık enerji üretimini hesaplayabilmek için kullanılan Jensen iz etkisi modeli incelenmiştir. İkinci olarak deniz kıyısında uzakta türbinleri yerleştirmek için belirlenen bölge için geliştirilen enerji üretim modelinde kullanılan parametreler ifade edilmiştir.

\section{1. İz etkisi}

Hava, rüzgâr türbinine yaklaştığında hızı düşer ve basıncı artar. Rüzgâr türbini rotorunu geçerken basınçta ani bir düşüş olur. Hemen rotorun aşağısındaki bölgede, basınç ve eksenel hızın dağılımı düzensiz şekilde azalır. Bu azalma, eksenel itme ile bağlantılı olan ve aynı zamanda makinedeki tork ile ilişkili olan azimut hız bileşenine bağlıdır. Bu durum arka arkaya iki rüzgâr türbini için incelenirse öndeki rüzgâr türbini arkasındaki rüzgâr türbinine ulaşan rüzgârın hızı azalmasına ve türbülans yoğunluğunun artmasına neden olur. Bu etkiye iz etkisi denilmekte ve rüzgâr türbinin y1llık enerji üretimini düşürmesinin yanı sıra türbinin ömrünün kısalmasına sebep olmaktadır (Hwang ve ark, 2015).

\subsection{Jensen iz etkisi modeli kullanılarak türbin yıllık enerji üretimin hesabı}

Türbinlerde iz düşümü etkisini hesaplamak için geçekleştirilen çalışmaların temelleri 1980’lere dayanmaktadır. Bu konuda gerçekleştirilen çalışmaların amacı iz düşümü etkisinden dolayı türbin üretiminde meydana gelecek üretim kaybını hesaplayabilmektir. Jensen modeli ise tek türbin iz alanının içindeki rüzgâr türbininin rüzgâr hızı düşümünü açıklamaktadır (Jensen, 1983). 


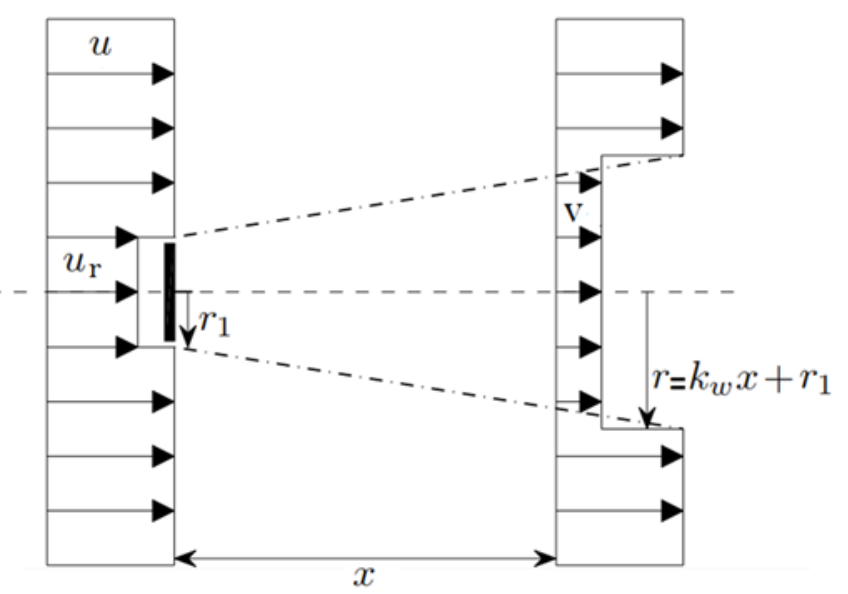

Şekil 1. Jensen iz etkisi modeli (Jensen, 1983).

Bu model, Şekil 1'de görüldüğü gibi rı yarıçaplı türbinden aşağıdaki r yarıçaplı iz alanına kadar aralarında yatay olarak x mesafesi bulunan iki türbin arasında doğrusal olarak genişleyen çapa sahip bir iz varsayımına dayanmaktadır. Burada bir kontrol hacmi boyunca momentum korunumu Denklem 1 'deki gibi ifade edilir.

$\pi r_{1}^{2} u_{r}+\pi\left(r-r_{1}\right)^{2} u=\pi r^{2} v$

Boyutsuz bir büyüklük olan $\mathrm{k}_{w}$ ise türbin iz alanının yatay mesafeyle ne kadar hızlı genişlediğini belirlemektedir ve Denklem 2'deki gibi tanımlanır.

$$
k_{w}=\frac{0.5}{\ln \left(\frac{Z}{z_{0}}\right)}
$$

Burada z, iz etkisi alanındaki türbinin göbek yüksekliği ve z0, yerel arazinin özelliklerine bağlı olarak değişkenlik gösteren yüzey pürüzlülük katsayısıdır. Jensen modelinde $k_{w}$ değerini sabit bir değer $\left(\mathrm{k}_{\mathrm{w}}=0.1\right)$ olarak kabul edilmektedir. Ancak, literatürde $\mathrm{k}_{\mathrm{w}}$ değeri kara üstü RES'ler için 0.075 ve deniz üstü RES'ler için ise 0.04'tür (Barthelmie ve ark., 2005; Thøgersen, 2005; Crastoa ve ark., 2012; Barthelmie ve Jensen, 2010).

Rüzgâr türbinin iz hacminde yatay olarak x mesafesindeki hız değeri, Denklem 1'de $u_{r}$ yerine $\sqrt{1-C_{T}}$ ifadesi yazılıp bu denklemin çözülmesiyle Denklem 3’teki ifade elde edilir.

$$
\left.v=u+u \sqrt{1-C_{T}}-1\right)\left(\frac{r_{1}^{2}}{r^{2}}\right)
$$


Burada u serbest rüzgâr hızını, v ise iz etkisi alanında kalan türbinin düşmüş rüzgâr hızını

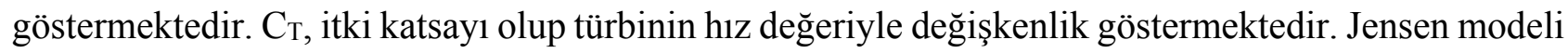
lineer hız düşümü modeli ile ifade edilecek olursa Denklem 4'teki eşitlik elde edilir. Bu ifadede önde bulunan türbinin iz alanı $\mathrm{A}_{\text {iz }}$ 'dir. $\mathrm{A}_{\text {çakışma }}$ ise öndeki türbinin iz alanı ile arkada bulunan türbinin çakışma alanının geometrik ifadesidir (Nielsen ve ark., 2009).

$$
\Delta u=u-v=u\left(1-\sqrt{1-C_{T}}\right)\left(\frac{A_{\text {çakışma }}}{A_{i z}}\right)
$$

Deniz üstü RES'lerde türbinlerin net üretim değeri, $0^{\circ}$ ile $360^{\circ}$ arasında değişen yön değerleri için $30^{\circ}$ 'lik 12 sektöre ayrılarak her bir sektörü için hesaplanmaktadır. Bu hesaplamada 2 parametreli (k ve A) Weibull olasılık yoğunluk fonksiyonu kullanılmaktadır. Bu fonksiyon Denklem 5'de ifade edilmiştir. Burada f(u) gözlemlenen rüzgâr hızı u'nun olasılık fonksiyonunu, k ile A ise sırasıyla şekil ve ölçek parametrelerini ifade etmektedir.

$f(u)=(k / A)(u / A)^{k-1} e^{-\left(\frac{u}{A}\right)}$

Bir rüzgâr türbininde iz etkisi nedeniyle her bir sektörde brüt üretim miktarı düşecektir. Bir rüzgâr türbini için yıllık net üretim değeri hesaplanırken Denklem 6'daki ifade kullanılmaktadır (Nielsen ve ark., 2009).

$$
N \ddot{U}=8760 \times f_{s} \times \int_{0}^{\infty} \delta(u-\Delta u) * p(u-\Delta u) * f(u) * d(u)
$$

Bu denklemde ilk ifade olan fs sektör frekansını ifade etmektedir. İkinci ifade olan $\delta(u-$ $\Delta \mathrm{u}$ ), türbinin devrede olup olmadığını göstermektedir. Eğer türbin üretim yapıyorsa bu değer "1" olacak aksi halde " 0 ” olacaktır. Üçüncü ifade $\mathrm{p}(\mathrm{u}-\Delta \mathrm{u})$, ise belirtilen sektördeki iz etkisinden dolay1 meydana gelen hız düşümünü sonucu yeni hız değerinin türbin güç eğrisindeki karşılığını ifade etmektedir. Son ifademiz $\mathrm{f}(\mathrm{u})$ ise hız düşümü olmadan önceki hız değerleri için A ve k katsayıları kullanılarak her sektör için hesaplanan olasılık yoğunluk fonksiyonudur.

Bir rüzgâr türbini için net üretim değeri, brüt üretimden iz etkisi nedeniyle meydana gelen kayıp çıkarılarak bulunur. Burada her bir rüzgâr türbini için brüt enerji üretimi hesaplanırken türbinin hız değeri, türbinin devreye girdiği hız ile devreden çıktığı hız değeri arasında birer birimlik aralıkların orta noktası alınarak hesaplanmaktadır. Bu hesaplamalar sonucunda her bir sektör için elde edilen brüt üretim değerleri toplanarak toplam brüt üretim değeri elde edilmektedir. Burada net üretim 
hesabında kullanılan Denklem $6^{`}$ daki ifade de $\Delta \mathrm{u}=0$ alınarak brüt enerji üretim değeri hesaplanmaktadir.

\subsection{Deniz kıyısında belirlenen bölge için saha verileri ve türbin parametreleri}

Bu bölümde deniz kıyısından uzakta bir bölgeye yerleştirilen türbinlerde iz etkisi modelinin üretimi nasıl etkilediği incelenmiştir. Bu süreçte öncelikle WAsP yazılımından deniz kıyısından uzakta bir bölge belirlenmiştir. Bu bölgeye iki adet 2 MW gücünde rüzgâr türbini Şekil 2'de görüldüğü gibi yerleştirilmiştir. Türbinlerin hız- güç eğrisi ve itki katsayısı $(\mathrm{Ct})$ Şekil 3'te verilmiştir. Şekil 3'e göre türbin $3 \mathrm{~m} / \mathrm{s}$ hızda devreye girmekte, $25 \mathrm{~m} / \mathrm{s}$ hıza kadar üretim gerçekleştirmekte ve 25 $\mathrm{m} / \mathrm{s}$ 'den sonra devreden çıkmaktadır. Ayrıca türbinin bazı karakteristik özellikleri ise Tablo 1'de özetlenmiştir.

Türbin yerleşimi için belirlenen konumlara ait her sektörün yüzde olarak rüzgâr hızlarının frekans dağılımları, şekil (k) ve ölçek parametreleri (A) katsayıları Tablo 2'de verilmiştir. Bu tabloda $0^{\circ}-360^{\circ}$ arasında değişen yön değerleri $30^{\circ}$ 'lik 12 sektöre ayrılmıştır. Hesaplamalarda her sektördeki brüt ve net enerji üretim hesabı bu bölümde verilen bilgiler kullanılarak gerçekleştirilmiştir.

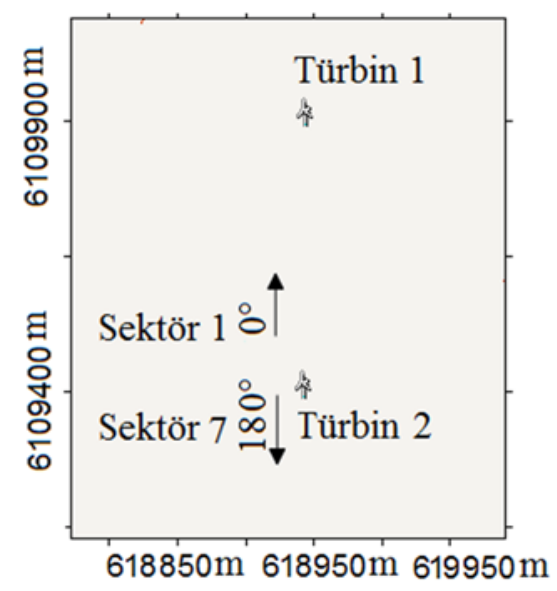

Şekil 2. Türbin yerleşimi için deniz kıyısından uzakta belirlenmiş koordinat bilgileri

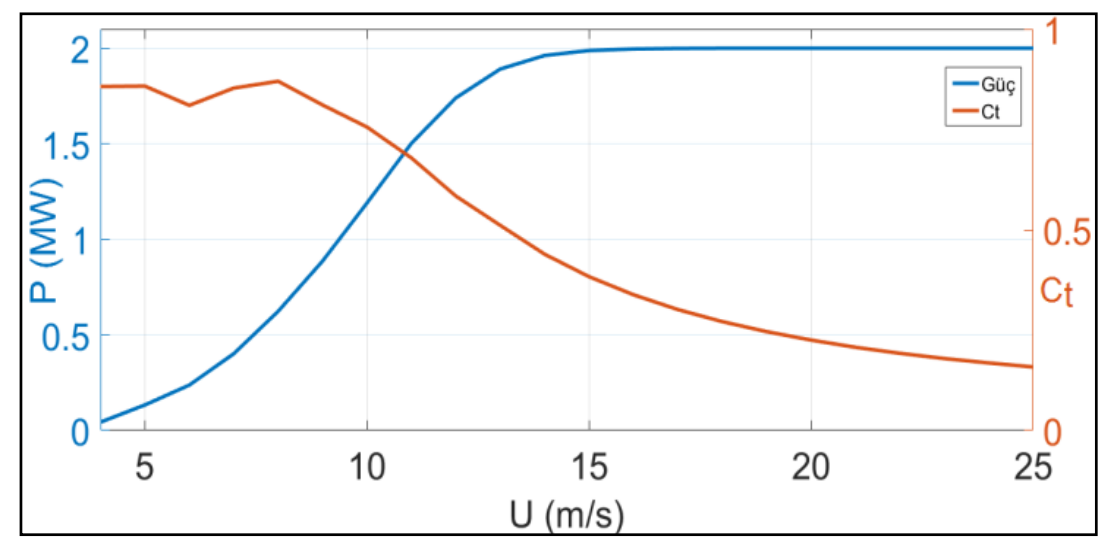

Şekil 3. 2 MW Bonus Türbin Hız güç eğrisi ve kapasite faktörü (Bonus,2019) 
Tablo 1. 2MW Bonus rüzgâr türbinlerinin sırasıyla karakteristik özellikleri (Bonus,2019)

\begin{tabular}{cc}
\hline Göbek yüksekliği $(\mathrm{m})$ & 60 \\
Rotor çapı $(\mathrm{m})$ & 76 \\
Devreye girme hızı $(\mathrm{m} / \mathrm{s})$ & 3 \\
Devreden çıkma hızı $(\mathrm{m} / \mathrm{s})$ & 25 \\
\hline
\end{tabular}

Tablo 2. Her sektör için frekans dağılımları ve Weibull katsayıları.

\begin{tabular}{ccccc}
\hline \multicolumn{5}{c}{ Sektör } \\
\hline Numaras1 & Aç1S1 & Frekans1 (\%) & Weibull-A (m/s) & Weibull-k \\
\hline 1 & 0 & 2.1 & 5.1 & 2.41 \\
2 & 30 & 4.5 & 6.4 & 2.49 \\
3 & 60 & 5.6 & 5.6 & 2.31 \\
4 & 90 & 7.5 & 5.8 & 3.23 \\
5 & 120 & 6.1 & 6.2 & 3.08 \\
6 & 150 & 5.4 & 6.5 & 2.84 \\
7 & 180 & 7.9 & 7.2 & 2.71 \\
8 & 210 & 8.4 & 8.6 & 2.78 \\
9 & 240 & 12.3 & 9.7 & 3.24 \\
10 & 270 & 15.7 & 9.7 & 2.75 \\
11 & 300 & 16.6 & 9.1 & 2.85 \\
12 & 330 & 8 & 7 & 2.40 \\
\hline
\end{tabular}

\section{Bulgular ve Tartışma}

Bu çalışmada kıyıdan uzakta iki adet rüzgâr türbininin birbirleri üzerinde oluşturdukları iz etkisi hesaplanarak bir rüzgâr türbininde sektörel olarak enerji üretimlerin nasıl etkilendiği incelenmiştir. $\mathrm{Bu}$ süreçte WAsP yazılımından faydalanarak çeşitli parametre değerleri kullanılarak MATLAB ortamında bir enerji üretim modeli oluşturulmuştur. Bu model sayesinde rüzgâr türbininin net ve brüt enerji üretim değerleri hesaplanmıştır. Bu modelde türbin 1, türbin 2'nin 1. sektöründe iz etkisi oluştururken türbin 2'de türbin 1'in 7. sektöründe iz etkisi oluşturmaktadır. Bu oluşturulan model ile WAsP yazılımından elde edilen sonuçlar türbinler arasındaki mesafenin $300 \mathrm{~m}$ ve $350 \mathrm{~m}$ olduğu durumlar için 1. ve 7. sektörlere ilişkin türbinlerin üretim sonuçları Tablo 3 'te verilmiştir.

Tablo 3. Türbinler arası farklı mesafeler için 1. ve 7. sektörlere ilişkin üretim sonuçları

\begin{tabular}{|c|c|c|c|c|c|c|}
\hline \multirow{3}{*}{$\begin{array}{l}\text { Türbin } \\
\text { Üretim } \\
\text { Mesafe (metre) }\end{array}$} & \multicolumn{4}{|c|}{ Türbin1 } & \multicolumn{2}{|c|}{ Türbin2 } \\
\hline & \multirow[t]{2}{*}{ Brüt } & \multicolumn{2}{|r|}{ Net } & \multirow[t]{2}{*}{ Brüt } & \multicolumn{2}{|c|}{ Net } \\
\hline & & 300 & 350 & & 300 & 350 \\
\hline WAsP (GWh) & 0.3080 & 0.1760 & 0.1970 & 0.029 & 0.0140 & 0.0160 \\
\hline Model (GWh) & 0.3030 & 0.1820 & 0.1900 & 0.029 & 0.0144 & 0.0155 \\
\hline Fark (\%) & 1.62 & 3.40 & 3.55 & 0 & 2.77 & 3.12 \\
\hline
\end{tabular}




\section{Sonuçlar ve Öneriler}

RES'lerde türbinlerin yerleştirildikleri konumlarından kaynaklı olarak birbirleri üzerinde iz etkisi oluşturmaktadırlar. Bu etki hem türbinlerin yıllık üretimlerini düşürmekte hem de yüksek türbülanstan dolayı türbinlerin ömürlerini kısaltmaktadır. Bir rüzgâr türbininde iz etkisinden dolayı meydana gelebilecek üretim düşüşünü hesaplamak önemli konulardan birisidir. Bu konuda birçok çalışma gerçekleştirilmiş olmakla birlikte Jensen modeli çok yaygın olarak kullanılmaktadır.

$\mathrm{Bu}$ çalışmada Jensen iz etkisi modeli kullanılarak MATLAB ortamında rüzgâr türbini enerji üretim modeli oluşturulmuştur. $\mathrm{Bu}$ modelin sonuçları WAsP yazımı ile kıyaslanmıştır. $\mathrm{Bu}$ kıyaslamaya göre MATLAB ortamında oluşturulan modelde $300 \mathrm{~m}$ ve $350 \mathrm{~m}$ mesafeler için ilk olarak türbin 2'nin türbin 1'e iz etkisi oluşturduğu 7. sektör için hesaplamalar gerçekleştirilmiştir. Bu hesaplamalarda brüt üretimin WASP yazılımı sonuçlarına göre çok küçük hata yüzdesi ile hesaplandığ1 görülmüştür. Net üretimin değerinin ise en fazla \% 3.55 hata ile hesaplandiğ 1 görülmüştür. Ayrıca türbin 1'in türbin 2'ye iz etkisi oluşturduğu 1. sektör için brüt üretim değeri WASP yazılımıyla aynı hesaplanmıştır. Net üretim değeri ise 300 metre mesafede $\% 2.77$ hata ile $350 \mathrm{~m}$ mesafede ise \% 3.12 hata ile hesaplanmıştır. Bu iki sektör için elde edilen sonuçlar, geliştirilen modelin deniz üstü RES'lerde rüzgâr türbini enerji üretim hesabında rahatlıkla kullanılabileceğini göstermiştir. $\mathrm{Bu}$ model sayesinde MATLAB ortamında farklı güçlerde ve mesafelerde rüzgâr türbinleri içinde enerji üretim hesabı gerçekleştirilebilecektir.

\section{Kaynaklar}

Asta S., (2013). A. survey on recent off-shore wind farm layout optimization methods, technical report. Nottingham, UK: University of Nottingham.

Barthelmie, R.J., Folkerts, L., Larsen, G.C., Rados, K., Pryor, S.C., Frandsen, S.T. (2005). Comparison of wake model simulations with offshore wind turbine wake profiles measured by sodar. $J$ Atmospheric Ocean Technoogyl, 23, 881-901.

Barthelmie, R.J, Hansen K., Frandsen, S.T., Rathmann, O., Schepers, J.G., Schlez, W. (2009). Modelling and measuring flow and wind turbine wakes in large wind farms offshore. Wind Energy, 12: 431-444.

Barthelmie, R.J., Jensen, L.E. (2010). Evaluation of wind farm efficiency and wind turbine wakes at the nysted offshore wind farm. Wind Energy, 13, 573-586.

Crastoa, G., Gravdahla, A., Castellanib, F., Piccionib, E. (2012). Wake modeling with the actuator disc concept. Energy Procedia, 24, 385-392.

Crespo, A., Hernandez, J., Frandsen, S.T. (1999). Survey of modelling methods for wind turbine wakes and wind farms. Wind Energy, 2, 1-24.

Emami, A., Noghreh, P. (2010). New approach on optimization in placement of wind turbines within wind farm by genetic algorithms. Renew Energy, 35: 1559-1564.

Frandsen, S.T. (1992). On the wind speed reduction in the center of large clusters of wind turbines. Journal of Wind Eng Ind Aerodyn, 39: 251-256.

Hao, L., Zuo L., Li, J., Li, B., He, Y., Huang Q. (Ekim, 2016) A wind turbine control method based on Jensen model, International Conference on Smart Grid and Clean Energy Technologies, (pp. 207-211), Chengdu, China 
Hwang, C., Jeon, J. H., Kim G. H., Kim, E., Park, M., Yu, K. (2015). Modelling and simulation of the wake effect in a wind farm, Journal of International Council on Electrical Engineering, 5(1), 74-77.

Jensen, N. (1983). A note on wind turbine interaction. Technical report Ris-M-2411. Roskilde, Denmark: Risø National Laboratory.

Katic, I., Højstrup, J., Jensen, N. (1986). A simple model for cluster efficiency. In: Proceedings of the European wind energy association conference and exhibition, Rome, Italy.

Kiranoudis, C.T., Maroulis, Z.B. (1997). Effective short-cut modelling of wind park efficiency. Renew Energy, $11,439-457$.

Kusiak, A., Song, Z. (2010). Design of wind farm layout for maximum wind energy capture. Renew Energy, $35,685-694$.

Marmidis, G., Lazarou, S., Pyrgloti, E. (2008). Optimal placement of wind turbines in a wind park using Monte Carlo simulation. Renew Energy, 33, 1455-1460.

Nielsen, M., Jørgensen, H. E., Frandsen, S. T. (2009). Wind and wake models for IEC 61400-1 site assessment. In EWEC 2009 Proceedings online EWEC.

Peña, A., Réthoré, P., Laan, M.P. (2016). On the application of the Jensen wake model using aturbulencedependent wake decay coefficient: the Sexbierum case. Wind Energy, 2016;19(4), 763-76

Porté-Agel, F., Wu, Y.T., Chen, C-H. (2013). A numerical study of the effects of wind direction on turbine wakes and power losses in a large wind farm. Energies, 6 (10), 5297-313.

Shakoora, R., Hassan, M. Y., Raheema, A., Wu, Y. K. (2016). Wake effect modeling: A review of wind farm layout optimization using Jensen's model Renewable and Sustainable Energy Reviews, 58, 1048-1059.

Thøgersen, M.L. (2005). Wind PRO/PARK: introduction to wind turbine wake modelling and wake generated turbulence. Technical report. Niels Jernes Vej 10, DK9220 Aalborg, Denmark: EMD International A/S

Tian L., Zhu, W., Shen, W., Zhao, N., Shen, Z. (2014) Development and validation of a new two-dimensional wake model for wind turbine wakes, Journal of Wind Engineering and Industrial Aerodynamics, 137, 90-99.

Turner, S.D.O., Romero, D.A., Zhang, P.Y., Amon, C.H., Chan, T.C.Y. (2014). A new mathematical programming approach to optimize wind farm layouts. Renewable Energy, 63, 674-680.

URL-1: Foxwell, D. (2019). https://www.owjonline.com/news/view,5-ways-offshore-wind-will-continuetodiversify-in-2019_56228.htm, (Erişim Tarihi: 21 Şubat 2019).

URL-2: Bonus 2MW Turbine, https://en.wind-turbine-models.com/turbines/121-bonus-b76-2000, (Erişim Tarihi: 21 Şubat 2019).

Vermeer, L., Sørensen, J., Crespo, A. (2003). Wind turbine wake aerodynamics. Prog Aerosp Sci, 39, 467510.

Zhang, M.H. (2015) Wind resource assessment and micrositing: science and engineering, Wiley. 